\title{
Therapeutic targeting of noncoding RNAs in hepatocellular carcinoma: Recent progress and future prospects (Review)
}

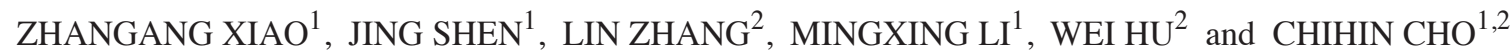 \\ ${ }^{1}$ Laboratory of Molecular Pharmacology, Department of Pharmacology, School of Pharmacy, \\ Southwest Medical University, Luzhou, Sichuan 646000; ${ }^{2}$ School of Biomedical Sciences, \\ Faculty of Medicine, The Chinese University of Hong Kong, Hong Kong SAR, P.R. China
}

Received November 2, 2016; Accepted October 18, 2017

DOI: $10.3892 / \mathrm{ol} .2018 .7758$

\begin{abstract}
Due to the high mortality rate and unsatisfactory treatment options available, hepatocellular carcinoma (HCC) remains one of the most common malignancies and a leading cause of cancer-associated mortality. Novel therapeutic targets for HCC are urgently required. Advanced RNA sequencing technology enables the identification of considerable amounts of noncoding RNAs (ncRNAs), including small noncoding RNAs and long noncoding RNAs, which exhibit no protein-coding activities. In this respect, ncRNAs and their regulatory processes are important factors in liver tumorigenesis. The present review focuses on the characteristics and biological roles of ncRNAs in HCC. Potential therapeutic applications of ncRNAs in HCC are also evaluated.
\end{abstract}

\section{Contents}

1. Introduction

2. sncRNAs in $\mathrm{HCC}$

3. IncRNAs in HCC

4. Conclusions

\section{Introduction}

Advanced RNA sequencing technology has facilitated the identification of substantial amounts of noncoding RNAs

Correspondence to: Dr Zhangang Xiao, Laboratory of Molecular Pharmacology, Department of Pharmacology, School of Pharmacy, Southwest Medical University, 319 Zhongshan Road, 3rd Section, Luzhou, Sichuan 646000, P.R. China

E-mail:xzg555898@hotmail.com

Professor Chihin Cho, School of Biomedical Sciences, Faculty of Medicine, The Chinese University of Hong Kong, Sha Tin, East New Territories, Hong Kong SAR, P.R. China

E-mail: chcho@cuhk.edu.hk

Key words: microRNA, small noncoding RNA, long noncoding RNA, piwi-interacting RNA, hepatocellular carcinoma, therapy
(ncRNAs). It was reported that up to $98 \%$ of the human genome encodes ncRNAs, which were previously considered to be transcriptional noise (1-3). Although they have no protein-coding capacity, these RNAs directly function as structural, catalytic and regulatory RNAs. Previous studies have demonstrated their ability to serve a plethora of roles in a variety of molecular functions including the regulation of transcription, splicing, and translation, in addition to the maturation of other ncRNAs which have been extensively reviewed previously (4-8). Small noncoding RNAs (sncRNAs), with a size of $<200$ nucleotides, were first identified by exogenous RNA interference (RNAi) in plants and nematodes, and were later found to exist endogenously (9). Currently, sncRNAs are classified as small interfering RNAs (siRNAs), microRNAs (miRNAs) and piwi-interacting RNA (piRNAs), which mainly function as gene-regulators in animals and plants by pairing to targeted genes and directing their post-transcriptional repression (10). Approximately 2,000 'high confidence' miRNAs have been reported in the human genome (miRBase 21, released July 3rd, 2014, http://www. mirbase.org/). Beyond the sncRNAs, the pervasive transcription of long noncoding RNAs (lncRNAs), with a size of $>200$ nucleotides, has also been discovered. IncRNAs include long intergenic noncoding RNAs, natural antisense transcripts, transcribed ultra-conserved regions and noncoding pseudogenes. Although the amount of lncRNAs is far greater than that of coding RNAs in mammals (11), the functions of the majority of lncRNAs remain unknown (12). Comprehensive analysis of published studies revealed three main modes of lncRNA-mediated regulation: i) Guiding the protein to a specific genomic region for gene regulation; ii) acting as the scaffold for the formation of functioning protein complex; and iii) competing with other factors for binding to the protein (13). An increasing amount of evidence demonstrates that ncRNAs play various biological roles in a wide range of cellular activities, including cellular function, pathways, motility, structure and stem cell biology $(14,15)$. For example, it was reported that the lncRNA HOTTIP promoted cell proliferation and migration via activating the $\mathrm{Wnt} / \beta$-catenin pathway (16). ncRNAs also serve regulatory functions in diverse pathological processes, including a number of malignancies (17-19). Due to the lack of studies on the majority of types of ncRNAs in HCC, the current review will focus on 
piRNA, miRNA and lncRNA, which have been extensively investigated in the pathogenesis of HCC.

\section{2. sncRNAs in HCC}

miRNAs in HCC. miRNAs are small molecules of 22 nucleotides in length, that are able to regulate gene expression by inhibiting target mRNA translation or by inducing mRNA degradation through partial or complementary binding to the 3 '-untranslated regions of target genes $(10,20)$. miRNAs are involved in numerous biological processes, including embryonic development, differentiation, proliferation, apoptosis, invasion and autophagy (21-24). Aberrant expression of miRNAs has been implicated in numerous diseases, including cancer (25). The roles of miRNAs in cancer can be oncogenic or tumor-suppressive, as the regulatory targets of the miRNAs determine their effect on carcinogenesis.

Extensive data from previous studies describe the multiple roles of miRNAs in HCC. Decreased or silenced expression of tumor-suppressive miRNAs have the potential to contribute to the pathogenesis of HCC through increasing the expression of their oncogenic targets. Previous studies have demonstrated that downregulation of tumor-suppressive miRNAs, such as miR-122a, miR-34a, miR-199a and miR-200, can lead to the activation of expression of their oncogenic targets in HCC (26-29). Meanwhile, the effect of increased oncogenic miRNAs, such as miR-21, miR-182 and miR-221, may also lead to the suppression of anti-oncogenes in HCC (30-32).

Accumulating evidence based on dysregulated miRNAs in HCC demonstrates the involvement of miRNAs in different stages of tumor progression (33-35). Previous studies also demonstrated that miRNA profiling enables the classification of various types of tumor including HCC (36), and that these profiles can act as signatures associated with diagnosis, prognosis and response to drug treatment in cancer $(36,37)$. Recently, circulating miRNAs were demonstrated to reflect different pathophysiological conditions of HCC, indicating that miRNAs may constitute promising and clinically useful biomarkers for this cancer type (38). Although vast quantities of miRNAs and their direct targets have been identified in HCC, the molecular mechanisms of interplay between miRNAs and their upstream regulators are still lacking. Previous studies identified that the expression levels of miRNAs are subject to transcriptional and post-transcriptional regulation, with miR-200, miR-20a, miR-106b and miR-941 were reported to be epigenetically regulated in HCC (39-41). Specific transcriptional factors, such as p53, heat shock transcription factor 1 and forkhead box D3, have been hypothesized to bind directly to miRNA promoters to regulate miRNA expression in liver cancer $(42,43)$.

piRNAs in HCC. piRNAs are small molecules of 26-31 nucleotides in length and are the largest class of known sncRNA molecules expressed in animal cells $(44,45)$. piRNAs interact with the PIWI subfamily of argonaute proteins to form functional RNA-protein complexes $(46,47)$, which developed as a conserved defense mechanism to protect the genetic information of animal germ cells from the detrimental effects of molecular parasites, such as transposons (48). piRNAs have been identified as regulators for the development and maintenance of DNA integrity by transcriptional or post-transcriptional gene silencing. Typically, such post-transcriptional gene silencing is sequence-specific and is subject to catalytically active enzymes (49-52). piRNAs can also direct gene regulation through chromatin modifications, including repressive histone marks and DNA methylation (53-55). It was also reported that piRNAs are involved in the epigenetic silencing of transposable elements (56).

PIWI proteins serve key roles in the biogenesis and functions of piRNAs by directly binding to piRNAs (57). Previous reports elucidated the function of the piRNA/PIWI axis in various human cancer types $(58,59)$. PIWI proteins are reported to be aberrantly and ectopically expressed in many cancer types, including HCC $(56,60-62)$. In these studies, PIWI proteins were found to exert multiple functional roles in cancer, such as promoting cell proliferation, inhibiting cell apoptosis, facilitating cell migration and invasion, regulating genomic integrity and acting as potential biomarkers for cancer diagnosis and prognosis. Regarding the specific role of PIWI proteins in HCC, it was reported that the expression of PIWI proteins, including PIWIL1, was increased in HCC cells, with depletion of this protein culminating in decreased invasion and metastasis $(62,63)$. Meanwhile, the presence of PIWI protein was also an independent risk factor affecting the overall survival and recurrence-free survival of HCC patients (62).

In addition to the crucial role of PIWI proteins in tumorigenesis, piRNAs also serve a vital role in this process. Certain piRNAs, such as tRNA-derived RNA fragments, may be associated with PIWI proteins in cancer cells (64). At present, numerous piRNAs have been identified to be associated with cancer pathology, including human piRABC, piR-Hep1, piR-651, piR-823, piR-932, piR-4987, piR-20365, piR-20485 and piR-20582. piRNAs are dysregulated in different cancer types, with functional investigations of these piRNAs demonstrating that these RNAs inhibited cell proliferation and colony formation, regulated cell cycle, promoted cell apoptosis, correlated well with clinical stages of patients, and decreased proangiogenic activity in cancer (60,65-73). However, only a few studies have reported the role of piRNAs in HCC. piR-Hep1 expression was upregulated in $~ 50 \%$ of hepatic tumors as compared with the corresponding adjacent tissues. Further studies identified that piR-Hep1 inhibited cell viability, motility and invasiveness in HCC (70), which provided novel insights into this cancer type. However further study is necessary to determine the role of piRNAs in HCC.

\section{Targeting sncRNAs in HCC therapy}

sncRNAs antagonism for HCC therapy. In conditions where miRNAs or piRNAs act as oncogenes in cancer, strategies involving the antagonism of miRNA or piRNA activity are desirable. Two broad categories of molecules can be applied to block sncRNAs: i) Oligonucleotide miRNA/piRNA inhibitors; and ii) RNA sponges containing the RNA oligonucleotides complimentary to the target miRNAs or piRNAs.

Nucleic acid inhibitors can inhibit endogenous miRNAs or piRNAs that exhibit tumor-promoting functions in cancer. An miR-122 inhibitor has been tested in phase 2 a clinical trials for treating patients with hepatitis $\mathrm{C}$ virus (HCV) infection. This provides a promising prospect for using antagonists of sncRNAs in liver disease therapy (74). Antagonists are 
typically chemically modified to bind to the target sncRNAs with high affinity. The functions of sncRNAs can be impeded or silenced by these antagonists due to antagonist sncRNA duplexes being unable to incorporate into the RNA-induced silencing complex as a result of high RNA duplex stability. Currently, the majority of advanced anti-miRNA therapies are in the preclinical stage; however, further studies are required to confirm their efficacy in cancer therapy. piRNA antagonists have also been reported in different cancer types (69). For example it was reported that piR-651 antagonists could induce cell cycle arrest in gastric cancer cells (69). Nevertheless, at present there are no studies reporting the use of piRNA antagonists in the treatment of HCC.

In addition to the nucleic acid inhibitors of miRNAs, researchers recently discovered that certain small molecules can also inhibit the expression of specific miRNAs in different cancer types; for example, inhibitors of miR-122 can inhibit HCV replication in liver cells (75). Additionally, a small molecule inhibitor of miR-525 was screened from a compound library, and it was revealed that this could inhibit the production of mature miR-525, upregulate the downstream protein ZNF395, and inhibit invasion of HCC cells (76). A powerful online database, The Connectivity Map, which uses gene-expression signatures to connect small molecules, genes, and disease $(77,78)$, has provided a novel way to identify potential modulators of sncRNAs for cancer therapy. The gene-expression profiles following the gain or loss of sncRNAs in cancer cells may be used to compare with the gene-expression profiles obtained from cells following treatment with different compounds.

sncRNA replacement for HCC therapy. Conversely, the loss of sncRNAs can be reversed via utilizing RNA mimics to correct RNA deficiency. To improve their endogenous protective mechanisms, RNA mimics have their own strands resembling the sequences of the respective targets. As miRNA mimics may exhibit similar functions to tumor-suppressive small ncRNAs in cancer cells, they are potential anti-cancer therapeutics. It is reported that the delivery of miR-26a mimics can inhibit tumor progression in a murine HCC model (79). Fang et al (80) also reported that miR-188-5p mimics suppressed HCC cell proliferation and metastasis in vitro and in vivo. Another previous study identified that miR-95a mimics inhibit HCC growth (81). In addition, a piRNA mimic of piR-015520 was demonstrated to repress the expression of its target gene, melatonin receptor $1 \mathrm{~A}(82)$. As such, the therapeutic effects involve the reactivation of pathways unfavorable to cancer cells.

In addition to the nucleic acid approach to sncRNA replacement (i.e., sncRNA mimics), certain small molecules have also been identified to activate the expression of sncRNAs in cancer. Various studies have screened small molecules that induce sncRNA expression in liver cancer. In HCC, Young et al (75) discovered that a small molecule may upregulate miR-122 in HCC cells, and subsequently upregulate caspase expression, culminating in apoptosis and reduced cell viability. Additionally, by screening from a nature products library, our previous study identified a small molecule named Rubone that may activate tumor-suppressive miR-34a expression in HCC cells (27). It was identified that miR-34a activation could increase miR-34a promoter activity via increasing p53 occupancy on the miR-34a promoter in wild type and mutant p53. Furthermore, our study demonstrated that a miR-34a activator significantly inhibited HCC cell growth and tumor growth by silencing the downstream oncogenic targets of this miRNA (27). However, small molecules that can modulate piRNA expression are still lacking. miRNA-based anti-HCC therapy has great potential, as reports have demonstrated that few adverse reactions would be caused in normal tissues when administered with an miRNA-based agent. The Connectivity Map tool may also be used to screen the activators of sncRNAs; for example, when gene expression profiles exhibit a high similarity following compound treatment or sncRNA overexpression, this indicates that the compound may be an activator of the corresponding sncRNA.

\section{IncRNAs in HCC}

Functional role of lncRNAs in HCC. The primary role of lncRNAs is to act as an adaptor that can mediate interactions between DNA, proteins and other RNAs (83). Previous mechanistic investigations revealed that lncRNAs exert their functional roles predominantly in two ways. First, they can bind directly to DNA or other RNA molecules (84). Second, lncRNAs may form secondary structures that function as binding sites for proteins or small molecules $(85,86)$. The aforementioned properties of lncRNAs may enable a much broader range of functions than with sncRNAs. Additionally, the increased number of binding sites that lncRNAs contain may allow more functional interactions when compared with sncRNAs. Studies have demonstrated that 1 ncRNAs serve critical roles in cellular processes, with specific lncRNAs possessing the ability to modulate cancer epigenomes and contribute to different pathological conditions, such as proliferation, apoptosis, metastasis, migration and epithelial-to-mesenchymal transition (EMT) (87-90). Consequently, comprehension of the molecular mechanisms of lncRNAs in tumor development and progression may provide a novel avenue in cancer therapy.

The roles of lncRNAs in HCC have been reported in recent publications (91-94). In these studies, the upregulated lncRNAs [including hepatocellular carcinoma upregulated long non-coding RNA (HULC); H19; PCBP2 overlapping transcript $1 /$ transcribed ultra conserved region 338; metastasis-associated lung adenocarcinoma transcript 1 (MALAT1); HOX transcript antisense RNA (HOTAIR); HOXA distal transcript antisense RNA (HOTTIP); hepatocellular carcinoma upregulated EZH2-associated long non-coding RNA (HEIH); ribosomal oxygenase 2/mineral dust-induced gene; plasmacytoma variant translocation 1 (PVT1); long intergenic non-protein coding RNA 974 (LINC00974); ubiquitin-fold modifier conjugating enzyme 1 (UFC1); PCNA antisense RNA 1; urothelial cancer-associated 1; colon cancer-associated transcript 1 (CCAT1); neutral amino acid transporter B (ATB); and upregulated in hepatocellular carcinoma (URHC)], in addition to the downregulated lncRNAs [including maternally expressed 3 (MEG3/GTL2); phosphatase and tensin homolog pseudogene 1 (PTENP1); long intergenic non-protein coding RNA 1018 (LINC01018/SRHC); and methallothionein 1D pseudogene (MT1DP)], are summarized in detail. In these studies, the lncRNAs in HCC were also divided into two 


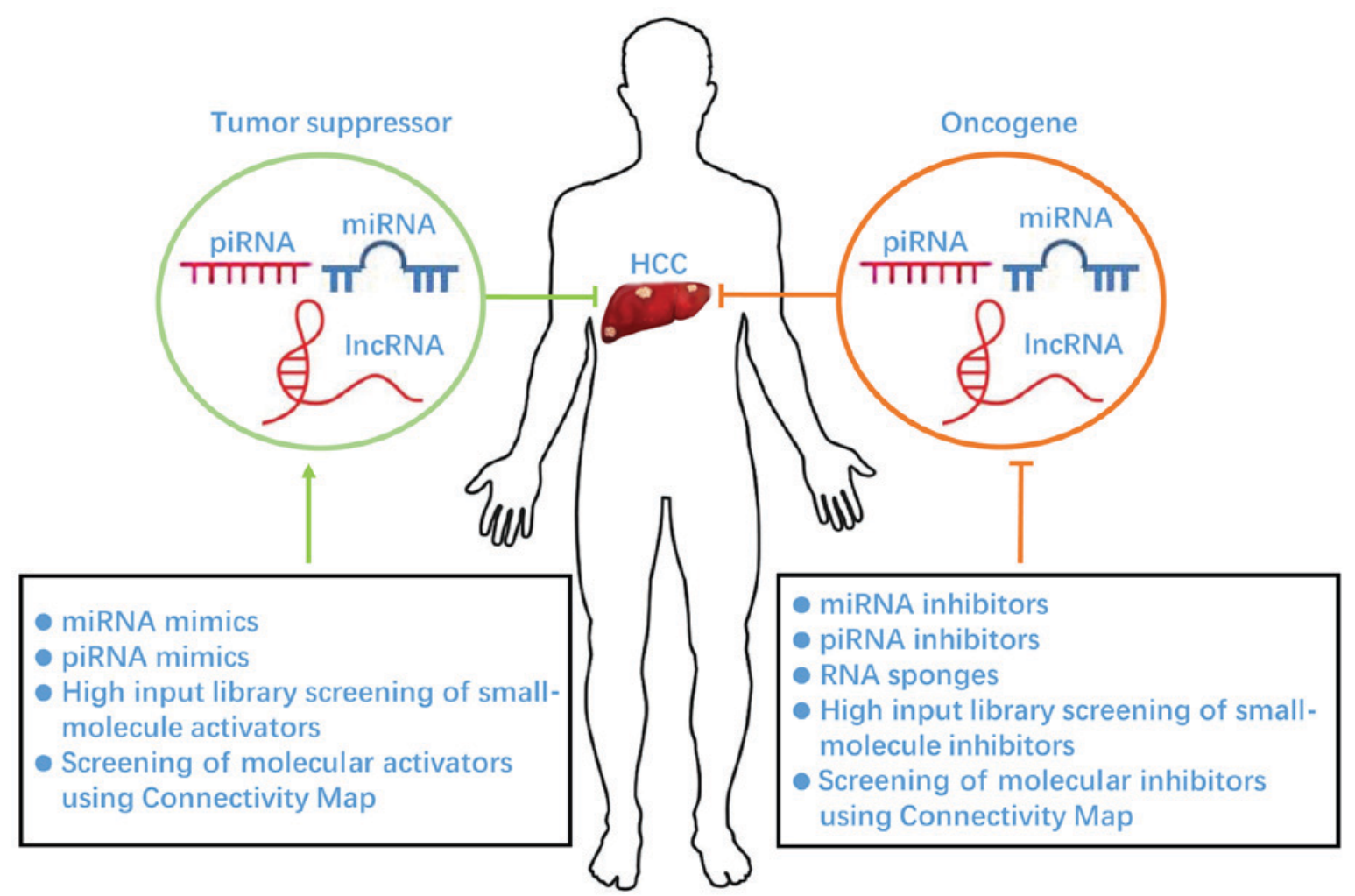

Figure 1. Therapeutic strategies for HCC via targeting noncoding RNAs. HCC, hepatocellular carcinoma; piRNA, piwi-interacting RNA; miRNA, microRNA; lncRNA, long noncoding RNA.

groups: i) lncRNAs associated with tumor growth and proliferation (such as PTENP1, MEG3, CCAT1, ZNRD1 antisense RNA 1, UFC1, lncRNA-hPVT1 and HULC); and ii) lncRNAs associated with metastasis and prognosis (such as H19, MALAT1, HOTAIR, HOTTIP, HEIH, ATB and lncRNA-p21). Tang et al (95) discovered novel lncRNAs associated with HCC that have also been identified to have multiple functions; for example LINC00974 can activate the transforming growth factor- $\beta$ and Notch signaling pathways, which promote the invasion and proliferation of HCC. High levels of URHC can inhibit tumor growth via activation of tumor-suppressive gene expression in HCC $(96,97)$. SRHC inhibited cell proliferation and promoted cell differentiation in HCC (98). MT1DP has demonstrated an ability to inhibit the transformative phenotype of liver cancer cells and cell proliferation (99). However, more preclinical models of HCC are required to provide more support for the clinical applications of lncRNAs.

Targeting lncRNAs in HCC therapy. Owing to the large amount of lncRNAs that have been implicated in HCC, these RNAs represent rational candidates for potential use in HCC therapy. According to previously published literature, in $\mathrm{HCC}$, a greater number of upregulated lncRNAs than downregulated lncRNAs have been identified $(94,100)$. Therapeutic strategies that reduce the endogenous transcript levels of lncRNAs may have more favorable results for HCC therapy. Currently, RNAi-based techniques are extensively used to inhibit lncRNAs in HCC cells. Du et al (101) reported that knockdown of HULC and MALAT1 by RNAi-based technique can inhibit HCC cell proliferation. It was also reported that using antisense oligonucleotides, which are short, single-stranded
DNAs or RNAs designed with antisense sequences of their target RNAs, could silence lncRNA function through degradation of lncRNA transcripts $(102,103)$. For example, antisense oligonucleotides directed against insulin-like growth factor-II mRNAs could delay the progress of HCC (104). Hammerhead ribozyme (HamRz) is another method to silence lncRNAs in liver cancer via destabilizing the phosphodiester backbone of its targets (105). Previous research has demonstrated that targeting lncRNAs with HamRz, has anti-cancer potential in different cancer types, including colorectal and lung (106). However, to date, there has been no research on the role of HamRz in HCC, which needs further study.

On the other hand, information on the secondary structure of lncRNAs can be utilized to screen potential modulators of this class of RNAs. The specificity and affinity of aptamers to the secondary structure of the target RNA are much higher than those of the complementary oligonucleotides (107). Although aptamers were reported to modulate lncRNAs through secondary structure interaction $(108,109)$, presently, there have been no studies examining this strategy in cancer therapy, which may be a novel direction for investigating modulators of lncRNAs in HCC.

Comparable to the strategy for screening the modulators of sncRNAs, small molecules also have the potential to modulate lncRNAs. Three compounds were identified to selectively modulate lncRNAs expression and subsequently repair various disorders in mice (110-112). Previous research demonstrated the feasibility of using a high-throughput screening method to identify modulators of lncRNAs (113). This could facilitate the development of a method utilizing small molecules to target lncRNAs that are dysregulated in $\mathrm{HCC}$ as a potential cancer 
therapy. The Connectivity Map tool is another strategy to elucidate modulators of lncRNAs in future studies.

\section{Conclusions}

HCC continues to be one of the most common malignancies and is a leading cause of cancer-associated fatalities due to its high mortality rate and the limited therapeutic options. Presently, sorafenib is the sole drug that has been approved for first-line treatment of HCC (114-116). Owing to recent failures of clinical trials undertaken to investigate novel drugs for HCC, the development of more effective drugs is urgently required.

ncRNAs exert their genomic regulation via transcriptional, post-transcriptional, and epigenetic modification, and the pathways that ncRNAs are involved in play crucial roles in HCC progression (Fig. 1). Various preclinical studies suggest that modulation of ncRNAs can elicit significant anti-cancer effects. In previous studies, a large number of ncRNAs, including miRNAs and lncRNAs, have been identified and several ncRNAs have been investigated in HCC (117). However, no ncRNAs have yet entered into clinical practice, with the exception of several that have been investigated in phase I and II clinical trials. HCC therapeutic treatments based on the targeting ncRNAs require further assessment. In addition, efficient delivery of agents to the targeted ncRNAs in HCC therapy remains a crucial issue. Nucleic acid-based drugs are well-established agents in targeting ncRNAs; however, the delivery of this drug type remains challenging including low biological stability and the poor tissue penetrance and cellular uptake, making it hard to pursue $(118,119)$. Meanwhile, nucleic acid-based drugs are usually poor in terms of accessibility into cancer cells. Small molecules with low molecular weight typically possess superior biological effects; numerous commonly used potent anti-cancer drugs, including erlotinib, gefitinib and sorafenib, are small molecules (120). Small molecules also show significant advantages for anti-cancer drug development for the following reasons: i) A wide range of small molecules can be synthesized within a short time; ii) compounds can be easily screened for interactions with a target; and iii) they are orally bioavailable and cost-effective (121). However, the safety of small molecule-based drugs must be established and verified. Therefore, nucleic acid and small molecule-based agents require further investigation in preclinical studies, and show promising potential as a drug of choice for HCC treatment in clinical practice.

\section{Acknowledgements}

This study was supported by grants from the National Natural Science Foundation of China (grant nos. 81503093, 81473269, 81602166 and 81672444).

\section{References}

1. International Human Genome Sequencing Consortium: Finishing the euchromatic sequence of the human genome. Nature 431: 931-945, 2004.

2. Yamada K, Lim J, Dale JM, Chen H, Shinn P, Palm CJ, Southwick AM, Wu HC, Kim C, Nguyen M, et al: Empirical analysis of transcriptional activity in the Arabidopsis genome. Science 302: 842-846, 2003

3. Pennisi E: Shining a light on the genome's 'dark matter'. Science 330: 1614, 2010.
4. He L and Hannon GJ: MicroRNAs: Small RNAs with a big role in gene regulation. Nat Rev Genet 5: 522-531, 2004.

5. Miska EA: How microRNAs control cell division, differentiation and death. Curr Opin Genet Devel 15: 563-568, 2005.

6. Nagano $T$ and Fraser P: No-nonsense functions for long noncoding RNAs. Cell 145: 178-181, 2011.

7. Rinn JL and Chang HY: Genome regulation by long noncoding RNAs. Ann Rev Biochem 81: 145-166, 2012.

8. Khanduja JS, Calvo IA, Joh RI, Hill IT and Motamedi M: Nuclear noncoding RNAs and genome stability. Mol Cell 63: 7-20, 2016.

9. Hannon GJ, Rivas FV, Murchison EP and Steitz JA: The expanding universe of noncoding RNAs. Cold Spring Harb Symp Quant Biol 71: 551-564, 2006.

10. Bartel DP: MicroRNAs: Target recognition and regulatory functions. Cell 136: 215-233, 2009.

11. Djebali S, Davis CA, Merkel A, Dobin A, Lassmann T, Mortazavi A, Tanzer A, Lagarde J, Lin W, Schlesinger F, et al: Landscape of transcription in human cells. Nature 489: 101-108, 2012.

12. Takahashi K, Yan I, Haga H and Patel T: Long noncoding RNA in liver diseases. Hepatology 60: 744-753, 2014.

13. Guttman M, Donaghey J, Carey BW, Garber M, Grenier JK, Munson G, Young G, Lucas AB, Ach R, Bruhn L, et al: lincRNAs act in the circuitry controlling pluripotency and differentiation. Nature 477: 295-300, 2011.

14. Tao H, Yang JJ and Shi KH: Non-coding RNAs as direct and indirect modulators of epigenetic mechanism regulation of cardiac fibrosis. Expert Opin Ther Targets 19: 707-716, 2015.

15. Fu XD: Non-coding RNA: A new frontier in regulatory biology. Nat Sci Rev 1: 190-204, 2014

16. Liao B, Chen R, Lin F, Mai A, Chen J, Li H, Xu Z and Dong S: Long noncoding RNA HOTTIP promotes endothelial cell proliferation and migration via activation of the Wnt/beta-catenin pathway. J Cell Biochem, 2017.

17. Peng JF, Zhuang YY, Huang FT and Zhang SN: Noncoding RNAs and pancreatic cancer. World J Gastroenterol 22: 801-814, 2016.

18. Zhang $\mathrm{M}$ and $\mathrm{Du} \mathrm{X}$ : Noncoding RNAs in gastric cancer: Research progress and prospects. World J Gastroenterol 22: 6610-6618, 2016

19. Adams BD, Parsons C, Walker L, Zhang WC and Slack FJ: Targeting noncoding RNAs in disease. J Clin Invest 127: 761-771, 2017.

20. Shukla GC, Singh J and Barik S: MicroRNAs: Processing, maturation, target recognition and regulatory functions. Mol Cell Pharmacol 3: 83-92, 2011

21. Marson A, Levine SS, Cole MF, Frampton GM, Brambrink T, Johnstone S, Guenther MG, Johnston WK, Wernig M, Newman J, et al: Connecting microRNA genes to the core transcriptional regulatory circuitry of embryonic stem cells. Cell 134: 521-533, 2008.

22. Bartel DP: MicroRNAs: Genomics, biogenesis, mechanism, and function. Cell 116: 281-297, 2004.

23. Shivdasani RA: MicroRNAs: Regulators of gene expression and cell differentiation. Blood 108: 3646-3653, 2006.

24. Wu SY, Lan SH and Liu HS: Autophagy and microRNA in hepatitis B virus-related hepatocellular carcinoma. World J Gastroenterol 22: 176-187, 2016.

25. Zhang L, Yu J, Wong CC, Ling TK, Li ZJ, Chan KM, Ren SX, Shen J, Chan RL, Lee CC, et al: Cathelicidin protects against Helicobacter pylori colonization and the associated gastritis in mice. Gene Ther 20: 751-760, 2013.

26. Tsai WC, Hsu SD, Hsu CS, Lai TC, Chen SJ, Shen R, Huang Y, Chen HC, Lee CH, Tsai TF, et al: MicroRNA-122 plays a critical role in liver homeostasis and hepatocarcinogenesis. J Clin Invest 122: 2884-2897, 2012.

27. Xiao Z, Li CH, Chan SL, Xu F, Feng L, Wang Y, Jiang JD, Sung JJ, Cheng CH and Chen Y: A small-molecule modulator of the tumor-suppressor miR34a inhibits the growth of hepatocellular carcinoma. Cancer Res 74: 6236-6247, 2014.

28. Hou J, Lin L, Zhou W, Wang Z, Ding G, Dong Q, Qin L, Wu X, Zheng Y, Yang Y, et al Identification of miRNomes in human liver and hepatocellular carcinoma reveals miR-199a/b-3p as therapeutic target for hepatocellular carcinoma. Cancer Cell 19: 232-243, 2011.

29. Zhang L, Yang F, Yuan JH, Yuan SX, Zhou WP, Huo XS, $\mathrm{Xu} \mathrm{D}, \mathrm{Bi}$ HS, Wang $\mathrm{F}$ and Sun SH: Epigenetic activation of the MiR-200 family contributes to H19-mediated metastasis suppression in hepatocellular carcinoma. Carcinogenesis 34: 577-586, 2013. 
30. Trebinjac S, Radulović R and Buljina A: Prevalence of gonarthrosis and the duration of rehabilitation. Med Arh 43: 179-182, 1989 (In Croatian).

31. Wang C, Ren R, Hu H, Tan C, Han M, Wang X and Zheng Y: MiR-182 is up-regulated and targeting Cebpa in hepatocellular carcinoma. Chin J Cancer Res 26: 17-29, 2014.

32. Park JK, Kogure T, Nuovo GJ, Jiang J, He L, Kim JH, Phelps MA, Papenfuss TL, Croce CM, Patel T and Schmittgen TD: miR-221 silencing blocks hepatocellular carcinoma and promotes survival. Cancer Res 71: 7608-7616, 2011.

33. Murakami Y, Yasuda T, Saigo K, Urashima T, Toyoda H, Okanoue T and Shimotohno K: Comprehensive analysis of microRNA expression patterns in hepatocellular carcinoma and non-tumorous tissues. Oncogene 25: 2537-2545, 2006.

34. Budhu A, Jia HL, Forgues M, Liu CG, Goldstein D, Lam A, Zanetti KA, Ye QH, Qin LX, Croce CM, et al: Identification of metastasis-related microRNAs in hepatocellular carcinoma. Hepatology 47: 897-907, 2008.

35. Ladeiro Y, Couchy G, Balabaud C, Bioulac-Sage P, Pelletier L, Rebouissou S and Zucman-Rossi J: MicroRNA profiling in hepatocellular tumors is associated with clinical features and oncogene/tumor suppressor gene mutations. Hepatology 47: 1955-1963, 2008.

36. Lu J, Getz G, Miska EA, Alvarez-Saavedra E, Lamb J, Peck D, Sweet-Cordero A, Ebert BL, Mak RH, Ferrando AA, et al: MicroRNA expression profiles classify human cancers. Nature 435: 834-838, 2005.

37. Xu Y, Huang J, Ma L, Shan J, Shen J, Yang Z, Liu L, Luo Y, Yao C and Qian C: MicroRNA-122 confers sorafenib resistance to hepatocellular carcinoma cells by targeting IGF-1R to regulate RAS/RAF/ERK signaling pathways. Cancer Lett 371: 171-181, 2016.

38. Afonso MB, Rodrigues PM, Simao AL and Castro RE: Circulating microRNAs as potential biomarkers in non-alcoholic fatty liver disease and hepatocellular carcinoma. J Clin Med 5 : E30, 2016.

39. Ning X, Shi Z, Liu X, Zhang A, Han L, Jiang K, Kang C and Zhang Q: DNMT1 and EZH2 mediated methylation silences the microRNA-200b/a/429 gene and promotes tumor progression. Cancer Lett 359: 198-205, 2015.

40. Yang H, Lan P, Hou Z, Guan Y, Zhang J, Xu W, Tian Z and Zhang C: Histone deacetylase inhibitor SAHA epigenetically regulates miR-17-92 cluster and MCM7 to upregulate MICA expression in hepatoma. Br J Cancer 112: 112-121, 2015.

41. Zhang PP, Wang XL, Zhao W, Qi B, Yang Q, Wan HY, Shuang ZY, Liu M, Li X, Li S and Tang H: DNA methylation-mediated repression of miR-941 enhances lysine (K)-specific demethylase 6B expression in hepatoma cells. J Biol Chem 289: 24724-24735, 2014.

42. Li Y, Xu D, Bao C, Zhang Y, Chen D, Zhao F, Ding J, Liang L, Wang Q, Liu L, et al: MicroRNA-135b, a HSF1 target, promotes tumor invasion and metastasis by regulating RECK and EVI5 in hepatocellular carcinoma. Oncotarget 6: 2421-2433, 2015.

43. Liu LL, Lu SX, Li M, Li LZ, Fu J, Hu W, Yang YZ, Luo RZ, Zhang CZ and Yun JP: FoxD3-regulated microRNA-137 suppresses tumour growth and metastasis in human hepatocellular carcinoma by targeting AKT2. Oncotarget 5: 5113-5124, 2014.

44. Kojima T: Kanagawa prefectural institute of public health. Chudoku Kenkyu 22: 266-269, 2009 (In Japanese).

45. Pantano L, Jodar M, Bak M, Ballescà JL, Tommerup N, Oliva R and Vavouri T: The small RNA content of human sperm reveals pseudogene-derived piRNAs complementary to protein-coding genes. RNA 21: 1085-1095, 2015.

46. Girard A, Sachidanandam R, Hannon GJ and Carmell MA: A germline-specific class of small RNAs binds mammalian Piwi proteins. Nature 442: 199-202, 2006.

47. Grivna ST, Beyret E, Wang Z and Lin H: A novel class of small RNAs in mouse spermatogenic cells. Genes Dev 20: 1709-1714, 2006.

48. Czech B and Hannon GJ: One loop to rule them all: The Ping-Pong cycle and piRNA-guided silencing. Trends Biochem Sci 41: 324-337, 2016.

49. Li C, Vagin VV, Lee S, Xu J, Ma S, Xi H, Seitz H, Horwich MD, Syrzycka M, Honda BM, et al: Collapse of germline piRNAs in the absence of Argonaute 3 reveals somatic piRNAs in flies. Cell 137: 509-521, 2009.

50. De Fazio S, Bartonicek N, Di Giacomo M, Abreu-Goodger C, Sankar A, Funaya C, Antony C, Moreira PN, Enright AJ and O'Carroll D: The endonuclease activity of Mili fuels piRNA amplification that silences LINE1 elements. Nature 480: 259-263, 2011.
51. Reuter M, Berninger P, Chuma S, Shah H, Hosokawa M, Funaya C, Antony C, Sachidanandam R and Pillai RS: Miwi catalysis is required for piRNA amplification-independent LINE1 transposon silencing. Nature 480: 264-267, 2011.

52. Wang W, Yoshikawa M, Han BW, Izumi N, Tomari Y, Weng Z and Zamore PD: The initial uridine of primary piRNAs does not create the tenth adenine that Is the hallmark of secondary piRNAs. Mol Cell 56: 708-716, 2014.

53. Pezic D, Manakov SA, Sachidanandam R and Aravin AA: piRNA pathway targets active LINE1 elements to establish the repressive H3K9me3 mark in germ cells. Genes Dev 28: 1410-1428, 2014.

54. Itou D, Shiromoto Y, Yukiho SY, Ishii C, Nishimura T, Ogonuki N, Ogura A, Hasuwa H, Fujihara Y, Kuramochi-Miyagawa $S$ and Nakano T: Induction of DNA methylation by artificial piRNA production in male germ cells. Current Biol 25: 901-906, 2015.

55. Yan H, Wu QL, Sun CY, Ai LS, Deng J, Zhang L, Chen L, Chu ZB, Tang B, Wang K, et al: piRNA-823 contributes to tumorigenesis by regulating de novo DNA methylation and angiogenesis in multiple myeloma. Leukemia 29: 196-206, 2015.

56. Ng KW, Anderson C, Marshall EA, Minatel BC, Enfield KS, Saprunoff HL, Lam WL and Martinez VD: Piwi-interacting RNAs in cancer: Emerging functions and clinical utility. Mol Cancer 15: 5, 2016

57. Juliano $\mathrm{C}$, Wang $\mathrm{J}$ and Lin $\mathrm{H}$ : Uniting germline and stem cells: The function of Piwi proteins and the piRNA pathway in diverse organisms. Ann Rev Genet 45: 447-469, 2011.

58. Moyano M and Stefani G: piRNA involvement in genome stability and human cancer. J Hematol Oncol 8: 38, 2015.

59. Assumpção CB, Calcagno DQ, Araújo TM, Santos SE, Santos ÂK, Riggins GJ, Burbano RR and Assumpção PP: The role of piRNA and its potential clinical implications in cancer. Epigenomics 7: 975-984, 2015.

60. Kwon C, Tak H, Rho M, Chang HR, Kim YH, Kim KT, Balch C, Lee EK and Nam S: Detection of PIWI and piRNAs in the mitochondria of mammalian cancer cells. Biochem Biophys Res Commun 446: 218-223, 2014.

61. Chen C, Liu J and Xu G: Overexpression of PIWI proteins in human stage III epithelial ovarian cancer with lymph node metastasis. Cancer Biomark 13: 315-321, 2013.

62. Zhao YM, Zhou JM, Wang LR, He HW, Wang XL, Tao ZH, Sun HC, Wu WZ, Fan J, Tang ZY and Wang L: HIWI is associated with prognosis in patients with hepatocellular carcinoma after curative resection. Cancer 118: 2708-2717, 2012.

63. Xie Y, Yang Y, Ji D, Zhang D, Yao X and Zhang X: Hiwi downregulation, mediated by shRNA, reduces the proliferation and migration of human hepatocellular carcinoma cells. Mol Med Rep 11: 1455-1461, 2015.

64. Keam SP, Young PE, McCorkindale AL, Dang TH, Clancy JL, Humphreys DT, Preiss T, Hutvagner G, Martin DI, Cropley JE and Suter CM: The human Piwi protein Hiwi2 associates with tRNA-derived piRNAs in somatic cells. Nucleic Acids Res 42: 8984-8995, 2014.

65. Hashim A, Rizzo F, Marchese G, Ravo M, Tarallo R, Nassa G, Giurato G, Santamaria G, Cordella A, Cantarella C and Weisz A: RNA sequencing identifies specific PIWI-interacting small non-coding RNA expression patterns in breast cancer. Oncotarget 5: 9901-9910, 2014.

66. Lu Y, Li C, Zhang K, Sun H, Tao D, Liu Y, Zhang S and Ma Y: Identification of piRNAs in Hela cells by massive parallel sequencing. BMB Rep 43: 635-641, 2010.

67. Cheng J, Deng H, Xiao B, Zhou H, Zhou F, Shen Z and Guo J: piR-823, a novel non-coding small RNA, demonstrates in vitro and in vivo tumor suppressive activity in human gastric cancer cells. Cancer Lett 315: 12-17, 2012.

68. Huang G, Hu H, Xue X, Shen S, Gao E, Guo G, Shen X and Zhang $\mathrm{X}$ : Altered expression of piRNAs and their relation with clinicopathologic features of breast cancer. Clin Trans Oncol 15: 563-568, 2013.

69. Cheng J, Guo JM, Xiao BX, Miao Y, Jiang Z, Zhou H and Li QN: piRNA, the new non-coding RNA, is aberrantly expressed in human cancer cells. Clin Chim Acta 412: 1621-1625, 2011.

70. Law PT, Qin H, Ching AK, Lai KP, Co NN, He M, Lung RW, Chan AW, Chan TF and Wong N: Deep sequencing of small RNA transcriptome reveals novel non-coding RNAs in hepatocellular carcinoma. J Hepatol 58: 1165-1173, 2013.

71. Chu H, Hui G, Yuan L, Shi D, Wang Y, Du M, Zhong D, Ma L, Tong N, Qin C, et al: Identification of novel piRNAs in bladder cancer. Cancer Lett 356: 561-567, 2015. 
72.Li PF, Chen SC, Xia T, Jiang XM, Shao YF, Xiao BX and Guo JM: Non-coding RNAs and gastric cancer. World J Gastroenterol 20: 5411-5419, 2014.

73. Zhang H, Ren Y, Xu H, Pang D, Duan C and Liu C: The expression of stem cell protein Piwil2 and piR-932 in breast cancer. Surg Oncol 22: 217-223, 2013.

74. Janssen HL, Reesink HW, Lawitz EJ, Zeuzem S, Rodriguez-Torres M, Patel K, van der Meer AJ, Patick AK, Chen A, Zhou Y, et al: Treatment of HCV infection by targeting microRNA. N Engl J Med 368: 1685-1694, 2013.

75. Young DD, Connelly CM, Grohmann C and Deiters A: Small molecule modifiers of microRNA miR-122 function for the treatment of hepatitis $\mathrm{C}$ virus infection and hepatocellular carcinoma. J Am Chem Soc 132: 7976-7981, 2010.

76. Childs-Disney JL and Disney MD: Small molecule targeting of a MicroRNA associated with hepatocellular carcinoma. ACS Chem Biol 11: 375-380, 2016.

77. Lamb J: The Connectivity Map: A new tool for biomedical research. Nat Rev Cancer 7: 54-60, 2007.

78. Toyoshiba H, Sawada H, Naeshiro I and Horinouchi A: Similar compounds searching system by using the gene expression microarray database. Toxicol Lett 186: 52-57, 2009.

79. Kota J, Chivukula RR, O'Donnell KA, Wentzel EA, Montgomery CL, Hwang HW, Chang TC, Vivekanandan P, Torbenson M, Clark KR, et al: Therapeutic microRNA delivery suppresses tumorigenesis in a murine liver cancer model. Cell 137: 1005-1017, 2009.

80. Fang F, Chang RM, Yu L, Lei X, Xiao S, Yang H and Yang LY: MicroRNA-188-5p suppresses tumor cell proliferation and metastasis by directly targeting FGF5 in hepatocellular carcinoma. J Hepatol 63: 874-885, 2015.

81. Xiao Z, Ching Chow S, Han Li C, Chun Tang S, Tsui SK, Lin Z and Chen Y: Role of microRNA-95 in the anticancer activity of Brucein D in hepatocellular carcinoma. Eur J Pharmacol 728 141-150, 2014

82. Esposito T, Magliocca S, Formicola D and Gianfrancesco F: piR_015520 belongs to Piwi-associated RNAs regulates expression of the human melatonin receptor $1 \mathrm{~A}$ gene. PLoS One 6 : e22727, 2011

83. Li X, Wu Z, Fu X and Han W: lncRNAs: Insights into their function and mechanics in underlying disorders. Mutat Res Rey Mutat Res 762: 1-21, 2014

84. Bonasio R, Tu S and Reinberg D: Molecular signals of epigenetic states. Science 330: 612-616, 2010.

85. Delihas N: Complexity of a small non-protein coding sequence in chromosomal region 22q11.2: Presence of specialized DNA secondary structures and RNA exon/intron motifs. BMC Genomics 16: 785, 2015.

86. Jenkins AM, Waterhouse RM and Muskavitch MA: Long non-coding RNA discovery across the genus anopheles reveals conserved secondary structures within and beyond the Gambiae complex. BMC Genomics 16: 337, 2015.

87. Dhamija S and Diederichs S: From junk to master regulators of invasion: lncRNA functions in migration, EMT and metastasis Int J Cancer 139: 269-280, 2016.

88. Huang B, Song JH, Cheng Y, Abraham JM, Ibrahim S, Sun Z, $\mathrm{Ke} X$ and Meltzer SJ: Long non-coding antisense RNA KRT7-AS is activated in gastric cancers and supports cancer cell progression by increasing KRT7 expression. Oncogene 35: 4927-4936, 2016

89. Zequn N, Xuemei Z, Wei L, Zongjuan M, Yujie Z, Yanli H, Yuping Z, Xia M, Wei W, Wenjing D, et al: The role and potential mechanisms of LncRNA-TATDN1 on metastasis and invasion of non-small cell lung cancer. Oncotarget 7: 18219-18228, 2016.

90. Zhuang J, Lu Q, Shen B, Huang X, Shen L, Zheng X, Huang R, Yan J and Guo H: TGF $\beta 1$ secreted by cancer-associated fibroblasts induces epithelial-mesenchymal transition of bladder cancer cells through lncRNA-ZEB2NAT. Sci Rep 5: 11924, 2015

91. Liu YR, Tang RX, Huang WT, Ren FH, He RQ, Yang LH, Luo DZ, Dang YW and Chen G: Long noncoding RNAs in hepatocellular carcinoma: Novel insights into their mechanism. World J Hepatol 7: 2781-2791, 2015.

92. Yang X, Xie X, Xiao YF, Xie R, Hu CJ, Tang B, Li BS and Yang SM: The emergence of long non-coding RNAs in the tumorigenesis of hepatocellular carcinoma. Cancer Lett 360: $119-124,2015$

93. Shibata C, Otsuka M, Kishikawa T, Ohno M, Yoshikawa T, Takata A and Koike K: Diagnostic and therapeutic application of noncoding RNAs for hepatocellular carcinoma. World J Hepatol 7: 1-6, 2015.
94. Huang JL, Zheng L, Hu YW and Wang Q: Characteristics of long non-coding RNA and its relation to hepatocellular carcinoma. Carcinogenesis 35: 507-514, 2014

95. Tang J, Zhuo H, Zhang X, Jiang R, Ji J, Deng L, Qian X, Zhang F and Sun B: A novel biomarker Linc00974 interacting with KRT19 promotes proliferation and metastasis in hepatocellular carcinoma. Cell Death Dis 5: e1549, 2014.

96. Xu WH, Zhang JB, Dang Z, Li X, Zhou T, Liu J, Wang DS, Song WJ and Dou KF: Long non-coding RNA URHC regulates cell proliferation and apoptosis via ZAK through the ERK/MAPK signaling pathway in hepatocellular carcinoma. Int J Biol Sci 10: 664-676, 2014.

97. Shonkoff JP: Building a new biodevelopmental framework to guide the future of early childhood policy. Child Dev 81: 357-367, 2010.

98. Zheng H, Yang S, Yang Y, Yuan SX, Wu FQ, Wang LL, Yan HL, Sun SH and Zhou WP: Epigenetically silenced long noncoding-SRHC promotes proliferation of hepatocellular carcinoma. J Cancer Res Clin Oncol 141: 1195-1203, 2015.

99. Yu W, Qiao Y, Tang X, Ma L, Wang Y, Zhang X, Weng W, Pan Q, $\mathrm{Yu} Y$, Sun F and Wang J: Tumor suppressor long non-coding RNA, MT1DP is negatively regulated by YAP and Runx2 to inhibit FoxA1 in liver cancer cells. Cell Signal 26: 2961-2968, 2014.

100. Li C, Chen J, Zhang K, Feng B, Wang R and Chen L: Progress and prospects of long noncoding RNAs (lncRNAs) in hepatocellular carcinoma. Cell Physiol Biochem 36: 423-434, 2015.

101. Du Y, Kong G, You X, Zhang S, Zhang T, Gao Y, Ye L and Zhang $X$ : Elevation of highly up-regulated in liver cancer (HULC) by hepatitis B virus $\mathrm{X}$ protein promotes hepatoma cell proliferation via down-regulating p18. J Biol Chem 287: 26302-26311, 2012.

102. Tripathi V, Ellis JD, Shen Z, Song DY, Pan Q, Watt AT, Freier SM, Bennett CF, Sharma A, Bubulya PA, et al: The nuclear-retained noncoding RNA MALAT1 regulates alternative splicing by modulating SR splicing factor phosphorylation. Mol Cell 39: 925-938, 2010.

103. Lin R, Roychowdhury-Saha M,Black C, Watt AT, Marcusson EG, Freier SM and Edgington TS: Control of RNA processing by a large non-coding RNA over-expressed in carcinomas. FEBS Lett 585: 671-676, 2011.

104. Ghosh MK, Patra F, Ghosh S, Hossain CM and Mukherjee B: Antisense oligonucleotides directed against insulin-like growth factor-II messenger ribonucleic acids delay the progress of rat hepatocarcinogenesis. J Carcinog 13: 2, 2014.

105. Tedeschi L, Lande C, Cecchettini A and Citti L: Hammerhead ribozymes in therapeutic target discovery and validation. Drug Discov Today 14: 776-783, 2009.

106. Pavco PA, Bouhana KS, Gallegos AM, Agrawal A, Blanchard KS, Grimm SL, Jensen KL, Andrews LE, Wincott FE, Pitot PA, et al: Antitumor and antimetastatic activity of ribozymes targeting the messenger RNA of vascular endothelial growth factor receptors. Clin Cancer Res 6: 2094-2103, 2000

107. Darfeuille F, Reigadas S, Hansen JB, Orum H, Di Primo C and Toulmé JJ: Aptamers targeted to an RNA hairpin show improved specificity compared to that of complementary oligonucleotides. Biochemistry 45: 12076-12082, 2006.

108. Kolb G, Reigadas S, Castanotto D, Faure A, Ventura M, Rossi JJ and Toulmé JJ: Endogenous expression of an anti-TAR aptamer reduces HIV-1 replication. RNA Biol 3: 150-156, 2006.

109. Watrin M, Von Pelchrzim F, Dausse E, Schroeder R and Toulme JJ: In vitro selection of RNA aptamers derived from a genomic human library against the TAR RNA element of HIV-1. Biochemistry 48: 6278-6284, 2009.

110. Pushechnikov A, Lee MM, Childs-Disney JL, Sobczak K, French JM, Thornton CA and Disney MD: Rational design of ligands targeting triplet repeating transcripts that cause RNA dominant disease: Application to myotonic muscular dystrophy type 1 and spinocerebellar ataxia type 3. J Am Chem Soc 131: 9767-9779, 2009.

111. Wheeler TM, Sobczak K, Lueck JD, Osborne RJ, Lin X, Dirksen RT and Thornton CA: Reversal of RNA dominance by displacement of protein sequestered on triplet repeat RNA. Science 325: 336-339, 2009.

112. Parsons J, Castaldi MP, Dutta S, Dibrov SM, Wyles DL and Hermann T: Conformational inhibition of the hepatitis $\mathrm{C}$ virus internal ribosome entry site RNA. Nat Chem Biol 5: 823-825, 2009.

113. Pedram Fatemi R, Salah-Uddin S, Modarresi F, Khoury N, Wahlestedt $\mathrm{C}$ and Faghihi MA: Screening for small-molecule modulators of long noncoding RNA-protein interactions using alphascreen. J Biomol Screen 20: 1132-1141, 2015 
114. Abou-Alfa GK, Schwartz L, Ricci S, Amadori D, Santoro A, Figer A, De Greve J, Douillard JY, Lathia C, Schwartz B, et al: Phase II study of sorafenib in patients with advanced hepatocellular carcinoma. J Clin Oncol 24: 4293-4300, 2006

115. Ben Mousa A: Sorafenib in the treatment of advanced hepatocellular carcinoma. Saudi J Gastroenterol 14: 40-42, 2008.

116. Waller LP, Deshpande V and Pyrsopoulos N: Hepatocellular carcinoma: A comprehensive review. World J Hepatol 7: 2648-2663, 2015.

117. George J and Patel T: Noncoding RNA as therapeutic targets for hepatocellular carcinoma. Semin Liver Dis 35: 63-74, 2015.

118. Shen J, Wu WK, Ren SX, Zhang L, Chan RL, Wong CC, Lu L and $\mathrm{Cho} \mathrm{CH}$ : miRNAs in gastrointestinal and liver cancers: Their perspectives and clinical applications. Curr Pharm Des 19: 1301-1310, 2013.
119. Movahedi F, Hu RG, Becker DL and Xu C: Stimuli-responsive liposomes for the delivery of nucleic acid therapeutics. Nanomedicine 11: 1575-1584, 2015.

120. Hoelder S, Clarke PA and Workman P: Discovery of small molecule cancer drugs: Successes, challenges and opportunities. Mol Oncol 6: 155-176, 2012.

121. Kuentz MT and Arnold Y: Influence of molecular properties on oral bioavailability of lipophilic drugs-mapping of bulkiness and different measures of polarity. Pharm Dev Technol 14: 312-320, 2009.

cc) (i) $\ominus$ This work is licensed under a Creative Commons EY NO NO Attribution-NonCommercial-NoDerivatives 4.0 International (CC BY-NC-ND 4.0) License. 